\title{
Exceeding the threshold value for Trioza apicalis Förster 1848 in carrot fields did not cause damage as revealed during monitoring in Germany from 2017-2020
}

\author{
J. Sauer ${ }^{1,4} \cdot$ A. Dewert ${ }^{1} \cdot$ P. Hondelmann ${ }^{3} \cdot$ R. Meyhöfer ${ }^{3} \cdot$ M. Hommes ${ }^{1} \cdot$ H. Buck ${ }^{2} \cdot$ C. Ulrichs $^{4} \cdot$ U. Vogler ${ }^{1}$
}

Received: 16 December 2020 / Accepted: 9 March 2021 / Published online: 25 March 2021

(c) The Author(s) 2021

\begin{abstract}
The carrot psyllid Trioza apicalis Förster 1848 is a carrot pest in Europe that can cause serious damages in case of massive occurrence. Damages up to a total loss of yield have been reported from Scandinavian countries but also from Switzerland. The action threshold to control the pest with chemical pesticides is $0.2 \mathrm{~T}$. apicalis per day and trap caught by sticky traps. We investigated the number of $T$. apicalis with sticky traps on carrot fields of the study regions Lüneburg/Uelzen and Hameln/Bad Pyrmont in Germany, during the period 2017-2020. The number of T. apicalis caught was generally very low in both study regions. On several fields in successive weeks almost no individuals were found in the study region Hameln/Bad Pyrmont. In Lüneburg/Uelzen was at least one field each year where the number of carrot psyllid was clearly higher than in all other fields and exceeded the threshold level. Surprisingly on carrot fields in close proximity to carrot fields from the previous year, the T. apicalis numbers were only slightly increased. Nonetheless, no loss of yield was reported for any of the fields in the four years of the study, although the generally defined threshold has been exceeded on many of the investigated carrot fields.
\end{abstract}

Keywords Carrot psyllid Trioza apicalis · Germany $\cdot$ Insect pest · Organic carrots $\cdot$ Monitoring

\section{Introduction}

The carrot psyllid Trioza apicalis (Hemiptera: Triozidae) was first described 1848 by Foerster in certain regions of Germany, namely in Aachen, Boppard and Harz mountains (Foerster 1848). It occurs as a pest insect in carrots (Daucus carota). Within Europe, occurrence of T. apicalis is reported

J. Sauer

jasmin.sauer@julius-kuehn.de

1 Federal Research Centre for Cultivated Plants, Institute for Plant Protection in Horticulture and Forests, Julius KuhnInstitute, Messeweg 11-12, 38104 Braunschweig, Germany

2 Naturland Fachberatung-Öko-BeratungsGesellschaft mbH, Bahnhofstraße 15b, 27374 Visselhövede, Germany

3 Institute of Horticultural Production Systems, Section Phytomedicine, Applied Entomology, Gottfried Wilhelm Leibniz Universität Hannover, Herrenhäuser Straße 2, 30419 Hannover, Germany

4 Division Urban Plant Ecophysiology, Faculty of Life Sciences, Thaer-Institute of Agricultural and Horticultural Science, Humboldt-Universität Zu Berlin, Lentzeallee 55-57, 14195 Berlin, Germany from France and Italy to Scandinavia (Burckhard 1985). The adults of T. apicalis appear in carrot fields in May/June for feeding and breeding (Nissinen 2012) and have only one generation per year. The new generation migrates to hibernation habitats in August/September. Kristoffersen and Anderbrant (2007) investigated the coniferous trees Norway spruce (Picea abies), Scots pine (Pinus sylvestris) and juniper (Juniperus communis) as hibernation sites and found most carrot psyllids in spruce trees only $250 \mathrm{~m}$ away from carrot fields. Remaining carrots on fields are also used for hibernation if available (Laska 1974). Laboratory investigations in Finland revealed, that carrot seedlings with up to five true leaves are particularly sensitive to psyllid feeding (Nissinen et al. 2014). Symptoms of infestation are described as curled and discoloured leaves, secondary root proliferation, and reduced weight of the root (Nissinen et al. 2014). Feeding of $T$. apicalis on carrot plants affects the yield and the quality of carrots, e.g., juiciness, content of suger and Vitamin C (Nissinen et al. 2012, Seljåsen et al. 2013). These investigations were carried out under laboratory conditions. Numerous laboratory tests and some field experiments describe the harmful potential of T. apicalis in northern Europe and Switzerland (Nissinen et al. 2012, Fischer et al. 2013). On 
carrot production sites, serious damage of carrots and loss of yield in the field caused by T. apicalis is reported mostly from the Scandinavian countries Finland, Sweden and Norway (Nissinen et al. 2008, Ragnarsson et al. 2016, Rygg 1977) and in Central Europe from Switzerland (Fischer et al. 2013). Hence, very little is known at which infestation level a loss of yield must be expected. For example, in Norwegian studies, no yield reduction is found due to a "low attack" of Trioza apicalis (Seljåsen et al. 2013), but on the other hand, yield levels were almost nil when "psyllas are abundant" (Markkula et al. 1976). On fields in Switzerland, more than 1000 psyllids were counted in one week on five sticky traps per field and 30-60 carrot psyllids per week were already described as moderate infestation (Fischer et al. 2013). For Germany, a yield reduction of $21-35 \%$ due to $T$. apicalis infestation was reported in Saxony-Anhalt in 1931, but no infestation level is mentioned (Bey 1931). Krumrey and Wendland (1973) reported carrot damages of 50\% up to $100 \%$, with an infestation level up to 68 carrot psyllids within 10 days in Bavaria, Germany. The action threshold to control T. apicalis with chemical pesticides was defined in Switzerland as 0.2 T. apicalis per day and trap (Sauer and Fischer 2014), based on studies of Fischer et al. 2013. They monitored the number of $T$. apicalis with five Rebell orange sticky traps per week and field.

Only little is known about the current numbers and harmful potential of T. apicalis in carrot fields in Germany. The present investigation aims to depict the current status of the T. apicalis presence in Lower Saxony/Germany and its potential to become a serious insect pest and to proof the validity of the defined Swiss threshold level and the adaptation for local carrot growing regions and local conditions in Lower Saxony.

\section{Material and methods}

\section{Field study sites}

A preliminary monitoring took place in 2015 and 2016 in the study regions Lüneburg/Uelzen and Hameln/Bad Pyrmont in Lower Saxony, Germany, to find field sites suitable for subsequent monitoring of $T$. apicalis. The monitoring was carried out on organically managed fields, with Naturland and Demeter certification. Selected fields of these organic farms were investigated for the subsequent monitoring of T. apicalis in the years 2017-2020. The number and location of fields examined changed in each study year. For the monitoring of T. apicalis, 13 fields were examined in 2017 (fields L1-L7 and H1-H6) and in 2018 (fields L8-L14 and H7-H13), 10 fields were examined in 2019 (fields L15-L19 and H14-H18) and five fields in 2020 (fields L20-L22 and H19-H20). The carrots were grown on dam cultivation.
Except of the fields L3, L10, L17 and L22, that were grown on flat field cultivation. Two farms in the Lüneburg/Uelzen region (Farm A and Farm B) grew carrots in 2017 and 2018 at directly adjacent fields. The fields of the two farms are about $30 \mathrm{~km}$ in linear distance. Carrots from Farm A could partially not be harvested in 2017, remained in the field and therefore represented an additional $T$. apicalis inoculum potential for the next years adjacent carrot field.

\section{Monitoring method}

Sauer and Fischer (2014) used five sticky traps for T. apicalis monitoring. The monitoring in this study was carried out with two Rebell ${ }^{\circledR}$ orange sticky traps (Rebell® orange Andermatt Biocontrol AG, Grossdietwil/Switzerland) per field. At the present time, we assume that two traps per field are sufficient. One trap was set up at the edge of the field to monitor the activity of $T$. apicalis at the edge of the field and another trap $20 \mathrm{~m}$ further inside the field to monitor the activity within the field. The traps were adjusted to the height of the crop. The monitoring took place from the beginning of May to the end of July, over a period of 12 weeks. The traps were changed weekly in the middle of the week. The counts of $T$. apicalis individuals were recorded per week using a binocular.

\section{Results}

The total numbers of caught $T$. apicalis varied greatly between the two study regions. More T. apicalis were caught in Lüneburg/Uelzen with 800 individuals, than in Hameln/ Bad Pyrmont with 147 individuals (Table 1), that indicates a higher infestation level in Lüneburg/Uelzen.

Overall, the abundance of $T$. apicalis decreased from 2017-2020 in both regions. While in Lüneburg/Uelzen, the number of total individuals decreased from 2017 to 2018 by about 20\%, they dropped by around 70\% from 2018 to 2019 . The decrease was more pronounced in Hameln/Bad Pyrmont by lower total numbers of caught $T$. apicalis individuals. $T$. apicalis numbers dropping continuously from 2017 to 2020 by more than $90 \%$. The only exception is the year 2020 in Lüneburg/Uelzen region. In contrast to the previous year, the number of T. apicalis increased from 77 individuals to 195 . However, this is only true for one of the three monitored fields, with carrot psyllids caught in high numbers (Fig. 1). The annual catch numbers for T. apicalis were highly variable between the fields within the same study region (Fig. 1). In both regions, the activity period of T. apicalis extended over a period of about four weeks. The activity of the insects within this period was different. In Lüneburg/ Uelzen, most of the T. apicalis caught between weeks 22-24 and in Hameln/Bad Pyrmont most of the insects caught in 
Table 1 Summerized total number and average number of recorded Trioza apicalis individuals on two traps in the two study regions. Lüneburg/ Uelzen and Hameln/Bad pyrmont in the twelve weeks of the monitoring seasons from May to July in the years 2017-2020

\begin{tabular}{|c|c|c|c|c|}
\hline \multirow[t]{2}{*}{ Year of monitoring } & \multicolumn{2}{|l|}{ Lüneburg/Uelzen } & \multicolumn{2}{|l|}{ Hameln/Bad Pyrmont } \\
\hline & $\begin{array}{l}\text { Total number over all } \\
\text { examined fields }\end{array}$ & $\begin{array}{l}\text { Average num- } \\
\text { ber per field }\end{array}$ & $\begin{array}{l}\text { Total number over all } \\
\text { examined fields }\end{array}$ & $\begin{array}{l}\text { Average } \\
\text { number per } \\
\text { field }\end{array}$ \\
\hline 2017 & 291 & 41.6 & 80 & 13.3 \\
\hline 2018 & 237 & 33.9 & 38 & 5.4 \\
\hline 2019 & 77 & 15.4 & 23 & 4.6 \\
\hline 2020 & 195 & 65 & 6 & 3 \\
\hline $\begin{array}{l}\text { Total number of T. apica- } \\
\text { lis from } 2017 \text { to } 2020\end{array}$ & 800 & & 147 & \\
\hline
\end{tabular}

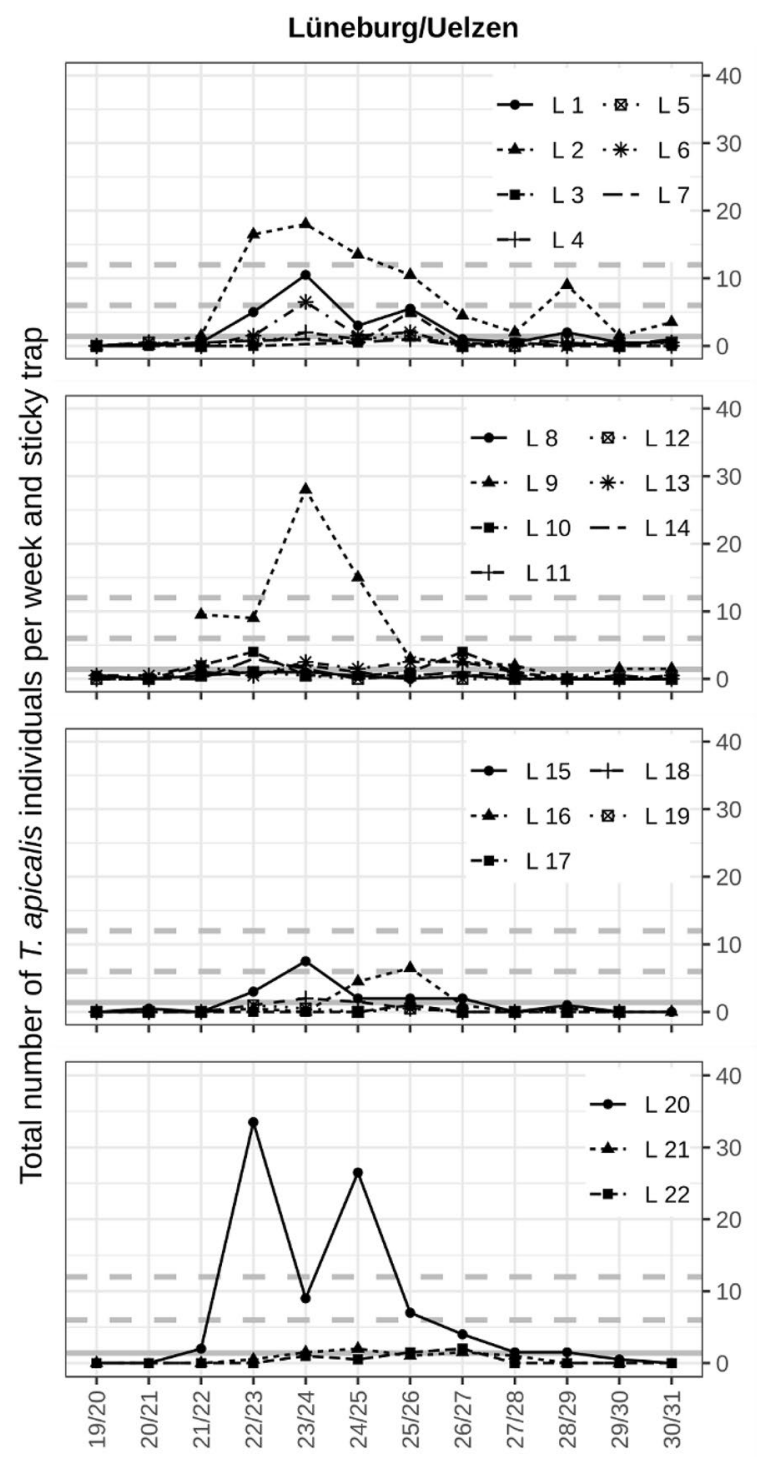

calendar week

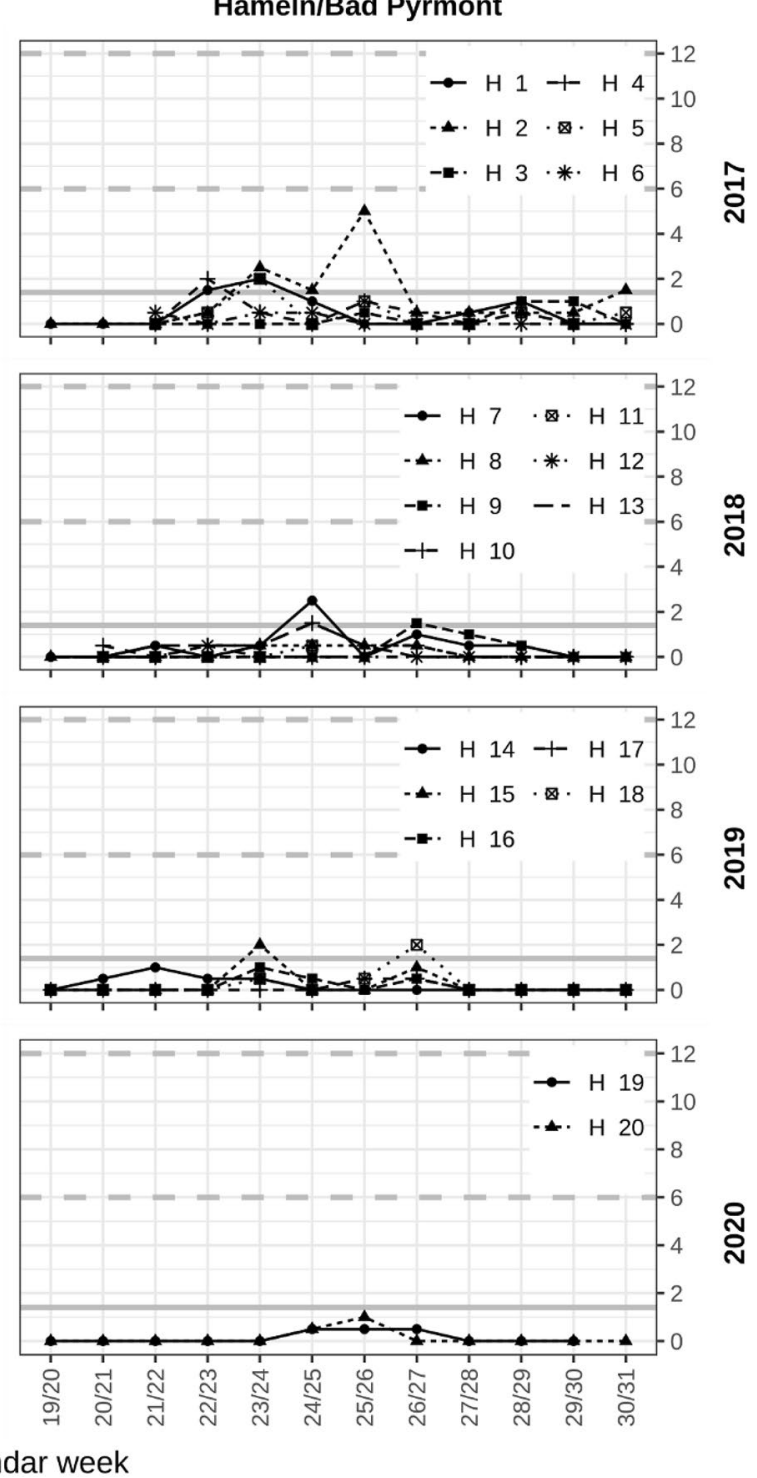

threshold level of 1.4 T. apicalis per week and trap, and the dotted grey line shows the moderate infestation level of 6-12 T. apicalis per week an trap. L1-L22 name the fields in Lüneburg/Uelzen and H1H20 the fields in Hameln/Bad Pyrmont.
Fig. 1 T. apicalis numbers on sticky traps from 2017 to 2020 in the two study regions. The weeks of the monitoring are shown on the horizontal axis. The vertical axis shows the number of $T$. apicalis that were caught per week and trap. The continuous grey line shows the 
weeks 24-27. Within this period, the threshold level was exceeded on several fields in both regions. We have scaled up the Swiss threshold from 0.2 T. apicalis per day and trap to 1.4 T. apicalis per week and trap (Fig. 1).

Nevertheless, the farmes reported no yield losses and were satisfied with the carrot yields in the years 2017-2020 in both study reagions. The two farms A and B located in Lüneburg/Uelzen grew carrots on fields next to each other in 2017 and 2018. These are the fields L2 and L9 of Farm A and the fields L7 and L13 of Farm B. The following graph (Fig. 2) shows in detail the number of T. apicalis in these adjacent fields.

In 2017, the threshold level was exceeded by a multiple on Farm A (Fig. 2). The situation was similar in 2018 and the number of T. apicalis even exceeded the previous year's level. On both farms, the number of T. apicalis increased in 2018 in the main activity period between weeks 22 and 26. In both years, the moderate level of 6-12 T. apicalis per week and trap (Fischer et al. 2013) was also exceeded. On Farm A, much more insects were caught overall than on Farm B. The number of carrot psyllids caught on Farm B in 2017 was below the threshold, but it exceeded the threshold in 2018. Compared to Farm A, the threshold on Farm B was only slightly exceeded. In both years, the number of $T$. apicalis from Farm B is in the range of those from Farm A, despite the increase in 2018.

\section{Discussion}

The defined threshold level from Switzerland is set to of 0.2 T. apicalis per day and trap, based on the harmful character of the carrot psyllid as a very dangerous insect pest in Switzerland. Here, we focused on the presence of carrot psyllids and the application of threshold levels in carrot growing regions in Lower Saxony, Germany. In our study, we only found small numbers of $T$. apicalis individuals compared with the $1.000 \mathrm{~T}$. apicalis per week found in Switzerland (Fischer et al. 2013). T. apicalis may have the potential to cause large damage to carrots with even small field populations and "in the case of small carrot seedlings, one psylla per plant is enough to cause an almost complete loss of the yield "(Markkula et al. 1976). We found T. apicalis numbers above the threshold level of 1.4 T. apicalis per week and trap on many fields; on some fields, the threshold was exceeded by a multiple. Interestingly no noteworthy or economically relevant yield loss was reported by the participating farms due to T. apicalis, although we have similar and more T. apicalis numbers compared with the Swiss threshold level. We assumed for German conditions, this low numbers of T. apicalis cannot be traceable as a threshold. The infestation level with the carrot psyllid rose if carrots are grown year after year
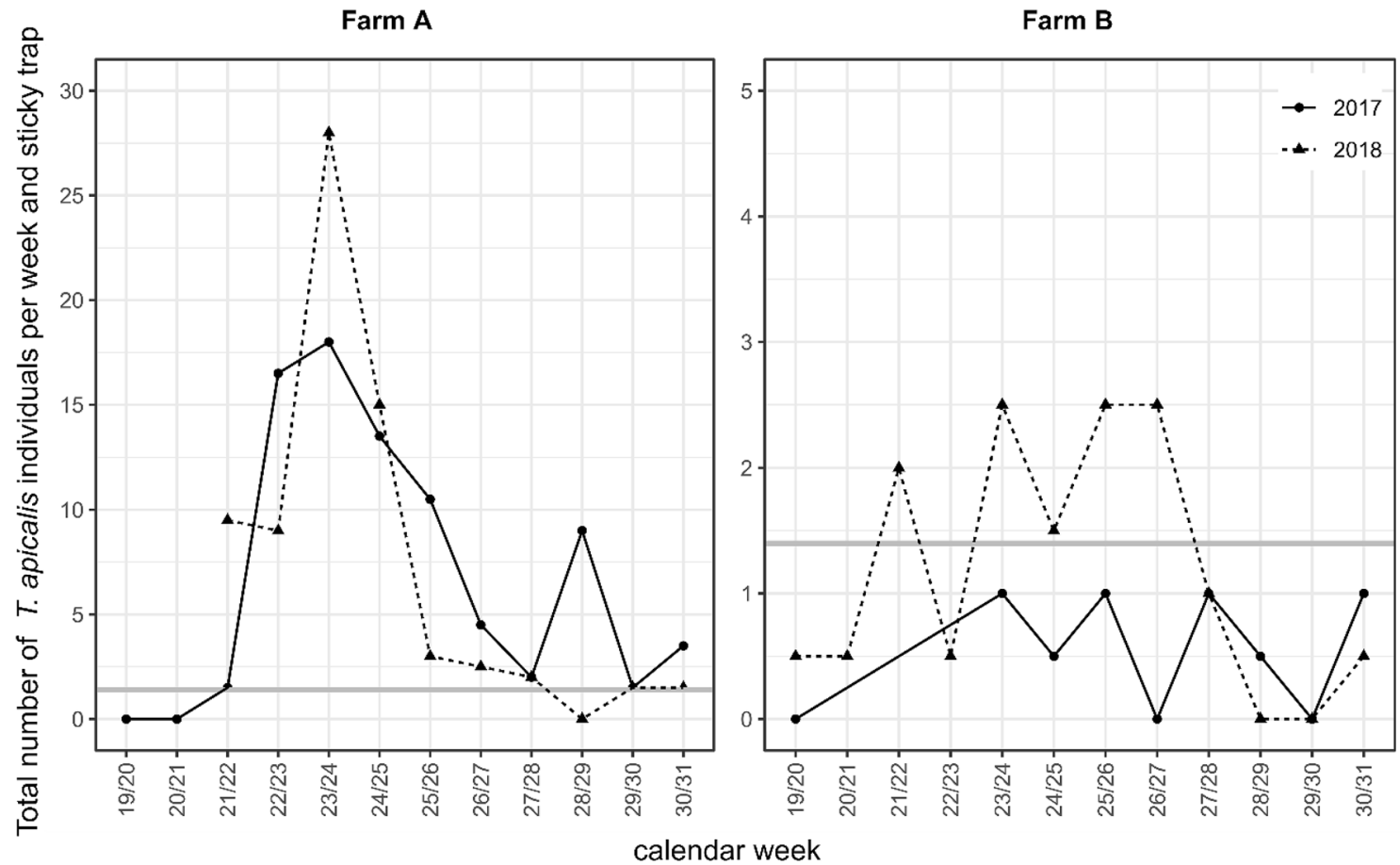

Fig. 2 T. apicalis numbers on adjacent carrot fields of Farm A and Farm B in 2017 and 2018. The horizontal axis shows the calendar week; the vertical axis shows the number of T. apicalis per week and

trap. The continuous grey line shows the threshold level of 1.4 T. apicalis per week and trap. 
on fields in close spatial vicinity. The insects only had to overcome a short distance from there hibernation site to the new carrot fields. Laska (1974) stated that carrot plants remaining in the field could serve as hibernation site for T. apicalis. Not all carrots were harvested on the field of Farm A in 2017. The insects had the opportunity to colonize the adjacent field in 2018 in a rapid way. The Swiss threshold on this field was, therefore, exceeded by a multiple and the moderate infestation level of 6 to $12 \mathrm{~T}$. apicalis per week and trap was exceeded without causing any remarkable yield losses. Neither Farm A with a high excess of the threshold nor Farm B with a low excess of the threshold has reported a relevant loss of carrot yield in 2018. Fischer et al. 2013) reported the Chablais in the Rhone valley (Switzerland) as one of the main areas of carrot cultivation in Switzerland, with regularly or episodically observed psyllid damage. The threshold level and moderate level were determined under Swiss scenarios, and therefore it also applies specifically to these areas and infestation conditions. In our study, threshold and moderate infestation level were exceeded on several fields in the study regions without leading to a loss of yield. For this reason, the T. apicalis numbers we found in our study are considered as low and the infestation level is considered as small. We conclude, the defined Swiss threshold value of $0.2 \mathrm{~T}$. apicalis per trap and day is set too low for the infestation levels of T. apicalis in the study regions in Germany. It remains an open question to determine the level of infestation at which yield-relevant losses are expected for our study regions in Germany and to define levels for high and moderate infestation. Establishing thresholds of yield-relevant loss levels require observing such losses over many years and to identify relevant influencing factors. Both the yield and T. apicalis populations are influencend by several different factors such as carrot varieties, local temperature, precipitation and wind data. The next step of investigation will be to evaluate these factors on T. apicalis numbers in carrot fields and the carrot yield.

Acknowledgements The authors kindly thank the farmers involved for making their fields available for field experiments and Manuel Holtgrewe for helping preparing the figures. The project is supported by funds of the Federal Ministry of Food and Agriculture (BMEL) based on a decision of the parliament of the Federal Republic of Germany via the Federal Office for Agriculture and Food (BLE) under the Federal Program for Ecological Farming and Other Forms of Sustainable Agriculture.

Authors' contributions JS, MH, HB planned and designed in the study. JS and AD performed the study and data acquisition. PH and HB contributed to the data acquisition. JS performed the data analysis. JS wrote the manuscript. $\mathrm{UV}, \mathrm{PH}, \mathrm{RM}, \mathrm{MH}, \mathrm{HB}$, and $\mathrm{CU}$ revised and edited the manuscript.

Funding Open Access funding enabled and organized by Projekt DEAL. The project is supported (was supported) by funds of the
Federal Ministry of Food and Agriculture (BMEL) based on a decision of the parliament of the Federal Republic of Germany via the Federal Office for Agriculture and Food (BLE) under the Federal Programme for Ecological Farming and Other Forms of Sustainable Agriculture.

Availability of data and material All data will be made available at any time upon request by readers.

Code availability Not applicable.

\section{Declarations}

Conflict of interest The research leading to these results received funding from the BMEL. The authors have no conflicts of interest to declare.

Ethical approval Not applicable.

Consent to participate All farmers agreed to participate in the study.

Consent for publication All participating farmers agreed to the publication of the data.

Open Access This article is licensed under a Creative Commons Attribution 4.0 International License, which permits use, sharing, adaptation, distribution and reproduction in any medium or format, as long as you give appropriate credit to the original author(s) and the source, provide a link to the Creative Commons licence, and indicate if changes were made. The images or other third party material in this article are included in the article's Creative Commons licence, unless indicated otherwise in a credit line to the material. If material is not included in the article's Creative Commons licence and your intended use is not permitted by statutory regulation or exceeds the permitted use, you will need to obtain permission directly from the copyright holder. To view a copy of this licence, visit http://creativecommons.org/licenses/by/4.0/.

\section{References}

Bey, N. S. 1931: Untersuchungen über Möhrenblattsauger, Aus der Zweigstelle Aschersleben der Biologischen Reichsanstalt für Land- und Forstwirtschaft

Burckhard D (1985) Taxonomy and host plant relationships of the Trioza apicalis Förster complex (Hemiptera, Homoptera: Triozidae). Ent Scand 16:415-432

Fischer S, Klötzli F, Terrettaz C (2013) Lutte contre le psylle de la carotte (Trioza apicalis) par le traitement des semences. Revue suisse Viticulture, Arboriculture, Horticulture 45(2):104-110

Foerster, A. 1848: Uebersicht der Gattungen und Arten in der Familie der Psylloden, Verhandlungen des naturhistorischen Vereins der preußischen Rheinlande

Kristoffersen L, Anderbrant O (2005) Host plant ecology of the carrot psyllid (Trioza apicalis). IOBC/WPRS Bull 28(4):129-132

Krumrey, G.\& Wendland, E. J. 1973: Versuchsergebnisse zur Bekämpfung des Mohrenblattflohes; Gesunde Pflanzen; ISSN : 0367-4223

Laska, P. 1974: Studie über den Möhrenblattfloh (Trioza apicalis Först.) (Triozidae, Homoptera)

Markkula M, Laurema S, Tiittanen K (1976) Systemic damage caused by Trioza Apicalis on carrot. In: Jermy $\mathrm{T}$ (ed) The host-plant in relation to insect behaviour and reproduction. Springer, Boston, pp 153-155 
Nissinen A, Kristoffersen L, Anderbrandt O (2008) Physiological state of female and light intensity affect the host-plant selection of carrot psyllid Trioza apicalis (Hemiptera: Triozidae). Eur J Entomol 105:227-232

Nissinen A, Lemmetty A, Pihlava J-M, Jauhiaainen L, Munyaneza JE, Vanhala P (2012) Effects of carrot psyllid (Trioza apicalis) feeding on carrot yield and content of sugars and phenolic compounds. Ann Appl Biol 161:68-80

Nissinen A, Haapalainen M, Jauhiainen L, Lindman M, Pirhonen M (2014) Different symptoms in carrots caused by male and female carrot psyllid feeding and infection by 'Candidatus Liberibacter solanacearum'. Plant Pathol 63:812-820. https://doi.org/10.1111/ ppa.12144

Ragnarsson S, Wikström M, Stegmark R (2016) Carrot psyllid-Swedish experience in practical farming and trials. Integr Prot Field Veg IOBC-WPRS Bull 118:61-67
Rygg, T. 1977: Biological Investigations on the carrot psyllid Trioza apicalis Förster (Homoptera, Triozidae); Norwegian Plant Protection Institute, Division of Entomology, 1432 As-NLH, Report No. 76

Sauer C. \& Fischer S. (2014) Schadschwellen im Deutschschweizer Gemüsebau, Teil 2: Salate, Liliengewächse und Doldenblütler; Agroscope Merkblatt Nr. 5/2014

Seljåsen R (2013) Influence of field attack by carrot psyllid (Trioza apicalis Forster) on sensory quality, antioxidant capacity and content of terpenes, falcarindiol and 6-methoxymellein of carrots (Daucus carota L.). J. Agric. Food Chem 61(11):2831-2838

Publisher's Note Springer Nature remains neutral with regard to jurisdictional claims in published maps and institutional affiliations. 